\title{
Evolutionary trends of the mitochondrial lineage differentiation in species of genera Martes and Mustela
}

\author{
Tetsuji Hosoda ${ }^{1}$, Hitoshi Suzuki ${ }^{2 *}$, Masashi Harada ${ }^{3}$, Kimiyuki Tsuchiya $^{4}$, \\ Sang-Hoon $\operatorname{Han}^{5}$, Ya-ping Zhang ${ }^{6}$, Alexei P. Kryukov ${ }^{7}$, \\ and Liang-Kong Lin $^{8}$ \\ ${ }^{1}$ Gobo Shoko High School, 43-1 Komatsubara, Yukawa, Gobo 644-0012, Japan \\ ${ }^{2}$ Division of Bioscience, Graduate School of Environmental Earth Science, Hokkaido \\ University, Kita-ku, Sapporo 060-0810, Japan \\ ${ }^{3}$ Laboratory Animal Center, Osaka City University Medical School, Abeno-ku, \\ Osaka 545-8585, Japan \\ ${ }^{4}$ Experimental Animal Center, Miyazaki Medical College, 5200 Kihara, \\ Kiyotake-cho, Miyazaki 889-1601, Japan \\ ${ }^{5}$ Korea Wildlife Information and Research Center, Seoul 130-011, Korea \\ ${ }^{6}$ Laboratory of Cellular and Molecular Evolution, Kunming Institute of \\ Zoology, Chinese Academy of Sciences, Kunming, \\ Yunnan 650223, China \\ ${ }^{7}$ Institute of Biology and Soil Science Russian Academy of Science, \\ Vladivostok 690022, Russia \\ ${ }^{8}$ Laboratory of Wildlife Ecology, Department of Biology, \\ Tunghai University, Taichung, Taiwan 407, R.O.C.
}

(Received 4 August 2000, accepted 25 October 2000)

We compared partial sequences (402 bp) of the mitochondrial cytochrome $b$ gene in 68 individuals of martens (Martes), weasels (Mustela) and their relatives from the Northern Hemisphere to identify the modes of geographic differentiation in each species. We then compared complete sequences $(1140 \mathrm{bp})$ of the gene in 17 species of the family Mustelidae to know the spatial and temporal modes of speciation, constructing linearized trees with transversional substitutions for deeper lineage divergences and with transversions and transitions for younger lineages. Our data suggested that these lineages of Martes and Mustela differentiated in a stepwise fashion with five radiation stages from the generic divergences (stage I) to the intraspecific divergences (stage V), during the last 10 or 20 million years as the fossil evidence suggests. In the lineage of Martes, the first offshoots are of Martes flavigula, M. pennanti, and Gulo gulo (stage II), the second is $M$. foina (stage III), and the third are $M$. americana, M. martes, M. melampus, and M. zibellina (stage IV). The divergence of the lineages of Mustela is likely to have taken place concurrently with the radiations of the Martes. These divergence processes are attributable in part to the geographic allocation along the two continents, North America and Eurasia, as well as among peripheral insular domains, such as Taiwan and the Japanese Islands. In addition, the Eurasian continent itself was shown to have been involved in the species diversification in the martens and weasels.

\section{INTRODUCTION}

The family Mustelidae, the most successful groups among the order Carnivora, is miscellaneous in species number, body size, habitat, and geographic space. Their

Edited by Toshihiko Shiroishi

* Corresponding author. E-mail: htsuzuki@ees.hokudai.ac.jp body size ranges from the tiny $35 \mathrm{~g}$ least weasel (Mustela nivalis), the smallest of all the carnivore species, to the 25 $\mathrm{kg}$ wolverine (Gulo gulo) and $35 \mathrm{~kg}$ sea otter (Enhydra lutris), 1000 times heavier. The family, which comprises 23 genera and 64 species (Corbet and Hill, 1991; 25 genera and 65 species in Wozencraft, 1993), has evolved into three major divisions: running and climbing types (weasels and martens), digging types with large claws (bad- 
gers) and swimming types (otters). Among the members of this family, the genera of Martes (martens) and Mustela (weasels and minks) are the most dominant, each having differentiated into various species and expanded their distribution across the entire Palaearctic region as well as to the American Continent.

The lineage of Martes with seven extant species (Corbet and Hill, 1991) has adapted to an arboreous habitat (climbing types). Three subgenera of Martes are recognized: Pekania Gray, the fishers (Martes pennanti); Charronia Gray, the yellow-throated marten (Martes flavigula); and Martes Pinel, the true marten (pine marten Martes martes, sable Martes zibellina, Japanese marten Martes melampus, American marten Martes americana, and beach marten Martes foina). The Holarctic species of Martes, Martes martes, Martes zibellina, Martes melampus, and Martes americana show many similarities in morphology, habits and habitat (Anderson, 1970). Unlike Martes martes and Martes foina whose ranges are sympatric, the four Holarctic species replace each other geographically: the four species are allopatrictheir combined ranges extend eastward from Britain to the Atlantic Coast of North America but do not overlap (Anderson, 1970).

The lineage of Mustela, on the other hand, has adapted to rather plain habitats, like grasslands. The Mustela, comprising 17 species (Corbet and Hill, 1991), have been differentiated into various morphological forms, especially in body size from small (e.g., weasel Mustela nivalis and stoat Mustela erminea) to large (e.g. steppe polecat Mustela eversmanni). Each species of Mustela now occurs over the two continents of Eurasia and America, coexisting with congeneric species, and shows substantial intraspecific geographic differentiation with respect to morphological, karyological and ecological features (Tate, 1947; Youngman, 1982; King, 1989), and sometimes these geographic forms are classified as different species.

To understand their evolutionary history, various molecular phylogenetic studies have been performed. A knowledge of the molecular phylogeny of the group of Mustelidae is being accumulated with analyses of DNADNA hybridization (Wayne et al., 1989), mitochondrial DNA (mtDNA; Masuda and Yoshida,1994a, 1994b; Carr and Hicks, 1995; Ledje and Arnason, 1996; Hosoda et al.,1997,1999; Koepfli and Wayne, 1998; Demboski et al., 1999; Kurose et al., 1999a, 1999b, 2000) and the nuclear ribosomal RNA gene spacers (Hosoda et al.,1993) but a comprehensive view of the molecular evolution is still to be achieved. Here we analyzed intra- and inter-specific variation in the mitochondrial cytochrome $b$ (cyt $b$ ) gene sequences in several species of the mustelid, especially those of Martes and Mustela. We attempted to obtain an evolutionary framework for these lineages and to reveal evolutionary trends that promoted the lineage differentiation.

\section{MATERIALS AND METHODS}

Animals Samples examined in this study are listed in Table 1. The German specimens were kindly sent by Kay Fuhrman, the Staatliches Museum, Oldburg, Germany. The occurrence of Mustela nivalis in Taiwan has been noted recently (L. K. Lin, unpublished) and its genetic basis has been clarified with the cytoplasmic cyt $b$ gene and nuclear ribosomal RNA gene markers (Hosoda et al., unpublished). The nomenclature was that of Corbet and Hill (1991) except for the Japanese weasel (Mustela itatsi), which can be regarded as a valid species from a morphological and ecological point of view (Abe, 1994).

Nucleotide sequencing of the cyt $\boldsymbol{b}$ gene Nested polymerase chain reactions (PCRs) and direct sequencing were performed as previously described (Suzuki et al., 2000). A 1.2-kb fragment of the gene for cyt $b$ was first amplified with the universal primers L14724 and H15915 (Irwin et al., 1991), in which the letters $\mathrm{L}$ and $\mathrm{H}$ refer to the light and heavy strands, and each number refers to the position of the 3 ' base of the primer in the complete sequence of human mtDNA (Anderson et al., 1981). In the second PCR, three segments were amplified against the first PCR product, with the following primer sets, R-L14724 and U-H15155 (Suzuki et al., 1997); R-L15131 and U-H15598 (Suzuki et al., 2000), and R-L15525 (5'CAGGAAACAGCTATGACCAGACAACTACATCCCCGCCAA3') and U-H15916 (Suzuki et al., 2000); and other mustelid-specific primers.

Sequence and tree analyses We obtained sequences of the cyt $b$ gene of the spot-necked otter Lutra maculicollis (AF057125), fisher Martes pennanti (AF057131), Eurasian badger Meles meles (X94922), Taiwanese weasel Mustela nivalis (AB046612), and Mustela putorius (X94925) from the database (DDBJ/EMBL/GenBank; Ledje and Arnason, 1996; Koepfli and Wayne, 1998). The sequences of the domestic cat Felis catus (AB004238), striped skunk Mephitis mephitis (X94927), and red fox Vulpes vulpes (X94929) from the database were used as an outgroup. Distances of Kimura (1980, Kimura's twoparameter) and Tamura and Nei (1993) were calculated using the computer software programs LINTRE (Takezaki et al., 1995) and MEGA (Kumar et al., 1993). Trees were constructed by the neighbor-joining (NJ) method (Saitou and Nei, 1987). We also constructed trees with the maximum parsimony (MP) and maximum likelihood (ML) methods using the software program PHYLIP (DNAPENNY for the MP method and DNAML for the ML method; Felsenstein, 1993).

We tested the hypothesis of a molecular clock for a given set of data using the method of the two-cluster test with the software program LINTRE (Takezaki et al., 1995). A linearized tree then was constructed for a given topol- 
Table 1. List of species used in this study

\begin{tabular}{|c|c|c|c|}
\hline Genus & Species (common name) & Source & Sample number and/or accession number* \\
\hline \multicolumn{4}{|l|}{ Martes } \\
\hline & M. americana (American marten) & Maine, USA & HS990\# \\
\hline & \multirow{2}{*}{$\begin{array}{l}\text { M. flavigula } \\
\quad \text { (yellow-throated marten) }\end{array}$} & Primorye region, Russia & HS1224 \# \\
\hline & & Kunming, China & HS844 \\
\hline & \multirow{2}{*}{ M. foina (beach marten) } & Thuringia, Germany & KF3TH213, KF4TH214, KF5TH215, KF7TH217 \\
\hline & & Kunming, China & HS1396\# \\
\hline & \multirow[t]{3}{*}{ M. martes (pine marten) } & Germany & КF9TH219, КF10TH220 \\
\hline & & Moscow region, Russia & HS1356\# \\
\hline & & Tver' region, Russia & HS1393 \\
\hline & \multirow{5}{*}{ M. melampus (Japanese marten) } & Hokkaido, Japan $^{\text {a }}$ & TH048 (AB029424)* \\
\hline & & Tochigi, Honshu, Japan & TH017 \\
\hline & & Shimane, Honshu, Japan & TH018 (AB029424)* \\
\hline & & Miyazaki, Kyushu, Japan & HS862 (AB029424)* \\
\hline & & Tsushima, Japan & TH004 (AB029426)*\#, TH007 (АB029426)* \\
\hline & M. pennanti (fisher) & - & AF057131*\# \\
\hline & \multirow{2}{*}{ M. zibellina (sable) } & Primorye region, Russia & VK183 (AB029420)*\# \\
\hline & & Hokkaido, Japan & $\begin{array}{l}\text { TH047 (AB029423)*, TH053 (AB029423)*, } \\
\text { TH107, (AB029423)*, HEG293 (AB029423)* }\end{array}$ \\
\hline \multicolumn{4}{|r|}{ 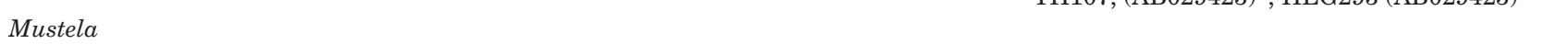 } \\
\hline & M. altaica (mountain weasel) & Altai mountains, Russia & TH147HS1516\#, TH148HS1517, TH149HS1518 \\
\hline & \multirow[t]{5}{*}{ M. erminea (stoat) } & Thuringia, Germany & KF17TH227 \\
\hline & & Novosibirsk, Russia & HS678, HS679 \\
\hline & & Hokkaido, Japan & TH106\# \\
\hline & & Iwate, Honshu, Japan & HEG305HS1759 \\
\hline & & Ishikawa, Honshu, Japan & MH7089 \\
\hline & M. eversmanni (steppe polecat) & Chita region, Russia & HS826 \\
\hline & \multirow[t]{2}{*}{$M$. itatsi (Japanese weasel) } & Aomori, Honshu, Japan & TH089 (AB029427)*\# \\
\hline & & Yakushima, Japan & HS1007 \\
\hline & M. lutreola (European mink) & Novosibirsk (farm), Russia & HS1225 \\
\hline & \multirow[t]{7}{*}{ M. nivalis (weasel) } & Germany & KF18TH228, KF19TH229, KF20TH230 \\
\hline & & Rostov region, Russia & HS1394 \\
\hline & & Primorye region, Russia & HS1119, HS1171 \\
\hline & & Korea & HS928 \\
\hline & & Hokkaido, Japan & TH104\#, HS597 \\
\hline & & Aomori, Honshu, Japan & HS686 \\
\hline & & Taiwan & TH133 (AB046612)*\# \\
\hline & \multirow[t]{3}{*}{ M. putorius (polecat) } & Germany & KF14TH224, KF15TH225, KF16TH226 \\
\hline & & Moscow region, Russia & HS1395 \\
\hline & & - & X94925*\# \\
\hline & \multirow{8}{*}{ M. sibirica (Siberian weasel) } & Primorye region, Russia & HS1121, HS1173, HS1183, HS1184 \\
\hline & & Pusan, Korea & TH052HS805 \\
\hline & & Mt. Chiri, Korea & TH056HS809 \\
\hline & & Sacheon, Korea & HS846 \\
\hline & & Tsushima, Japan & TH051HS804 \\
\hline & & Wakayama, Honshu, Japan ${ }^{\text {a }}$ & TH067, TH098\# \\
\hline & & Fukuoka, Kyushu, Japan $^{\text {a }}$ & TH100, TH101, TH102 \\
\hline & & Taiwan & HS1145, HS1146\# \\
\hline & M. vison (American mink) & - & AF057129*\# \\
\hline \multicolumn{4}{|c|}{ Other genera of Mustelidae } \\
\hline & Enhydra lutris (sea otter) & Alaska, USA (captivity) & TH257HS1749\# \\
\hline & Gulo gulo (wolverine) & Sakhalin, Russia & TH150HS1603\# \\
\hline & Lutra maculicollis (spot-necked otter) & - & $\mathrm{AF} 057125^{*} \#$ \\
\hline & Meles meles (Eurasian badger) & - & X94922*\# \\
\hline & Mephitis mephitis (striped skunk) & - & X94927*\# \\
\hline
\end{tabular}

* Sequences deposited in DDBJ/EMBL/GenBank International Nucleotide Sequence Database were used in this study.

\# Taxa subjected to phylogenetic analysis with 1140 bp sequence data.

a Population known to be introduced artificially from an other geographic area. 
ogy under the assumption of rate constancy using LINTRE. In the construction, the topology resulting from the NJ tree construction was used sharing the same distance (Kimura's distance). The estimation of branch lengths (i.e., heights of nodes) was performed with LINTRE in consideration of either all substitutions $(d)$ or transversions $(d \mathrm{v})$.

\section{RESULTS}

We compared cyt $b$ gene sequences $(402 \mathrm{bp})$ in 68 individuals of Martes and Mustela (Table 1). A NJ tree was constructed (Fig. 1) based on sequence divergences $(d)$ calculated by Kimura's (1980) two parameter method in consideration of all substitutions and all codon positions. The tree exhibited a species specific lineage differentiation that was supported by high bootstrap values ( $>75 \%)$, except for a clade of, Mustela eversmanni, Mustela lutreola, and Mustela putorius. The paraphyletic relationship that was seen in this clade may suggest that Mustela eversmanni and Mustela lutreola have speciated from Mustela putorius recently in evolutionary terms, though we do not exclude the possibility of problems of taxonomy and gene introgression. Here we regarded the three taxa as a single species lineage in the following analysis, since the level of sequence divergence $(d<0.013)$ was comparable to that of intraspecific variation as was observed in Martes zibellina $(d<0.013)$, Mustlea erminea $(d<0.013)$, Mustela. nivalis $(d<0.011)$, Mustela sibirica $(d<0.018)$, and Mustela itatsi $(d=0.005$, between the mainland Honshu vs insular population Yakushima). In contrast, a sister species group of Martes martes and Martes zibellina (Anderson, 1980) showed an apparent monophyletic state with considerable extent of sequence divergence $(d=0.018-0.025)$. In Martes foina, the haplotypes from Germany were found to be markedly differentiated from those of China $(d=$ ca. 0.022).

In a comparison of the intraspecies difference, the closest pair of mtDNA types would tell us the maximum time span over which genetic exchange has been interrupted across the populations. The levels of sequence divergence among distantly separated geographic populations were smaller than we initially expected in Martes flavigula and Mustela nivalis. In Mustela nivalis, the minimum sequence divergence between the populations of Germany and Honshu, Japan, was $0.0025(d)$, suggesting recent genetic communication between the localities. Similarly, in Martes flavigula, the sequence of Russia (Vladivostok) differed from that of Kunming, South China by only two bases $(d=0.005)$. In addition, no substantial partition of the mtDNA haplotypes was observed in Mustela sibirica from Russia and Korea, though two haplotype groups with considerable sequence divergence $(d=$ ca. 0.013$)$ were detected in the same geographic area. Our Mustela sibirica data revealed that an introduced population of the main- land Japan and a natural population of the Tsushima Islands (Abe, 1994) possessed different haplotype groups. In Mustela itatsi endemic to Japan, we examined two individuals from both peripheral regions of the native distribution, one from the most northern tip of Honshu (Aomori Prefecture) and the other from the Yakushima Island (the southern part of the Japanese Islands), which have been separated by the habitation of the introduced Mustela sibirica in the western part of the Japanese Islands. The Mustela itatsi haplotypes differed respectively by two bases along the $402 \mathrm{bp}$ sequence.

To clarify deeper lineages including the relationships between genera of the family Mustelidae, we performed sequence analysis of the entire gene (1140 bp) in 14 representative individuals of genera, Enhydra, Gulo, Martes, amd Mustela (Table 1). Combining four database sequences of Mustelidae (Lutra maculicollis, Martes pennanti, Meles meles, and Mustela putorius), we constructed NJ and linearized trees using sequence divergences of transversional substitutions $(d v)$, which are thought to be tolerated for deeper divergence (Irwin et al., 1991). The sequences for Felis catus, Mephitis mephitis, and Vulpes vulpes were used as an outgroup. In the tree with outgroup Vulpes vulpes, the two-cluster test (Takezaki et al., 1995) showed that the branch Meles meles was significantly long at the 5\% level. Then we eliminated the taxon of Meles meles in our further analysis. NJ trees obtained using Felis catus, Mephitis mephitis,or Vulpes vulpes as an outgroup were constructed with sequence divergence of $d \mathrm{v}$. We also constructed ML and MP trees as well as NJ trees with transversional distances calculated by the Tamura and Nei's (1993) method. These analyses clearly indicated that the taxa examined can be integrated into the three main lineages of LutraEnhydra, Martes-Gulo, and Mustela. The branching pattern of these lineages, however, was shown to be labile and unable to be resolved with current sets of mtDNA data through tree construction by the NJ, MP and ML methods with either of the outgroup species. For example, in the NJ trees, the Mustela lineage branched off first in the tree with Vulpes vulpes, whereas the Martes lineage branched first in the tree with Felis catus.

To illustrate the lineage differentiation with time, linearlized trees were constructed with the 20 complete cyt $b$ gene sequences (including the Mephitis mephitis sequence) using the computer program LINTRE (Takezaki et al., 1995). First, a $d v$ tree was constructed with sequence divergences of transversions $(d \mathrm{v})$. The rate constancy for the 20 mustelid taxa was found to be moderate in the two-cluster test examined. Because the resolutions of the splitting patterns of the $d \mathrm{v}$ tree were considered to be weak at lower nodes, we replaced those portions with more reliable ones. We constructed linearized trees in the group of Eurasian weasels (node 1) with outgroup Mustela vison and in the group of true martens (node 2) 


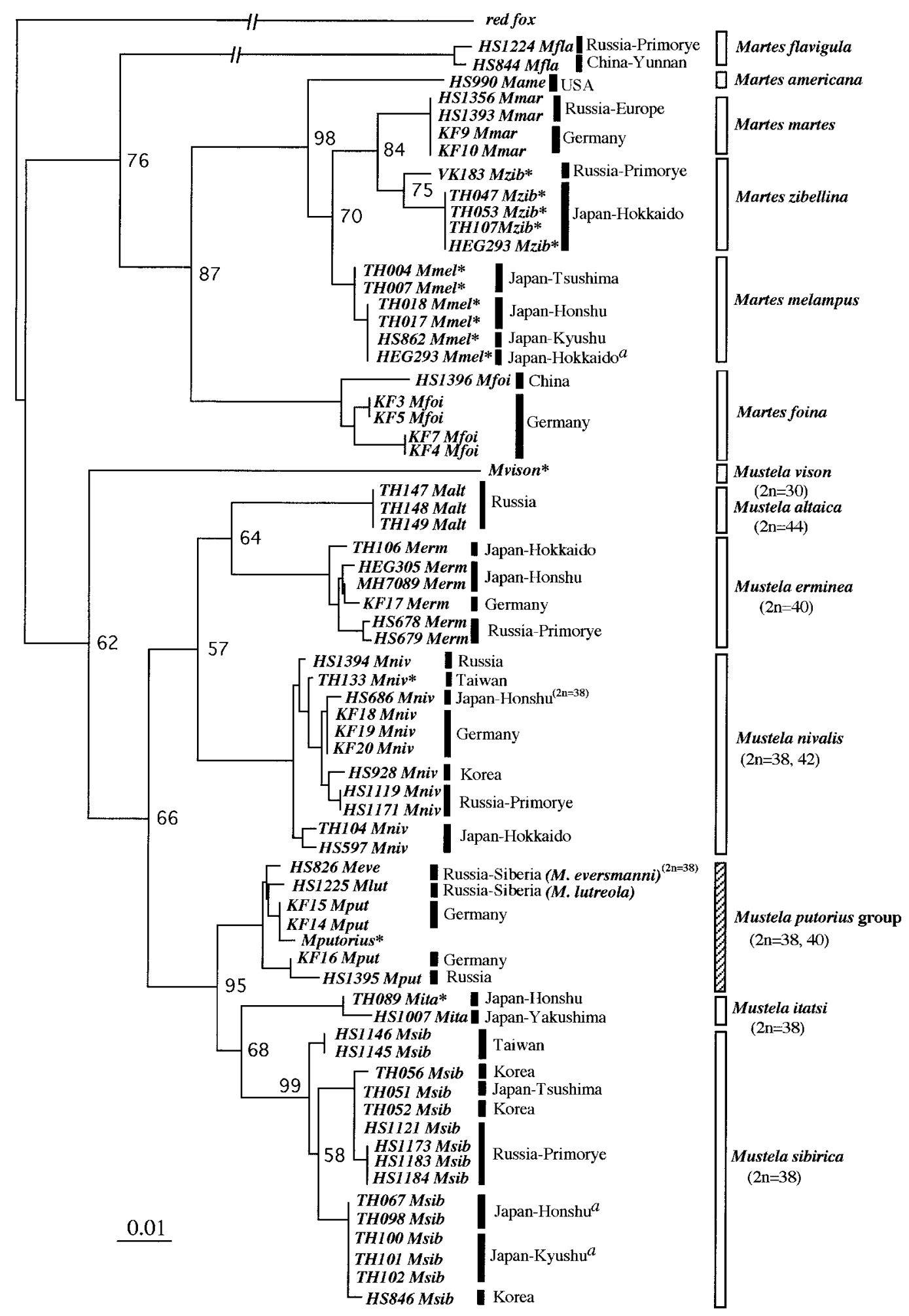

Fig. 1. Neighbor-joining tree of the cytochrome $b$ gene $(402 \mathrm{bp})$ with 68 individual sequences of martes (Martes) and weasels (Mustela). Pairwise sequence divergences $(d)$ were calculated by Kimura's (1980) two-parameter method considering all codon positions and all substitutions. Bootstrap scores with 1000 replicates are given associated with each node (\%). See Table 1 for the code names of samples (or accession numbers for sequences from the database) and representative names of collection localites. The sequences marked with asterisks were obtained from the database. Those populations that are thought to be established by artificial introduction are marked with the superscript 'a'. Abbreviations of the samples are the same as in Table 1. The diploid numbers presented are from the literature (Graphodatsky et al., 1976; Obara, 1991). 
with outgroup Martes flavigula, using distance matrices of $d$. The rate constancy for each lineage of the two linearized trees was assured to be moderate at the $5 \%$ level in the two-cluster test. We replaced the clade of Eurasian weasels at node 1 with that of the $d$ tree (the heights of node 1 were 0.0055 and 0.0447 in the $d v$ and $d$ trees, respectively), and then the true marten clade with that of the $d$ tree taking account of the height of node 2 of the $d$ tree (0.0453). The fusion tree obtained is shown in Fig. 2, and hopefully provides the most conceivable picture of the evolutionary relationships of the mustelid taxa examined here.

The evolutionary processes of differentiation for the members of Mustelidae can be categorized into five stages, which we tentatively designated as stages I-V. The first divergence is the splitting of the three clades, Lutra-

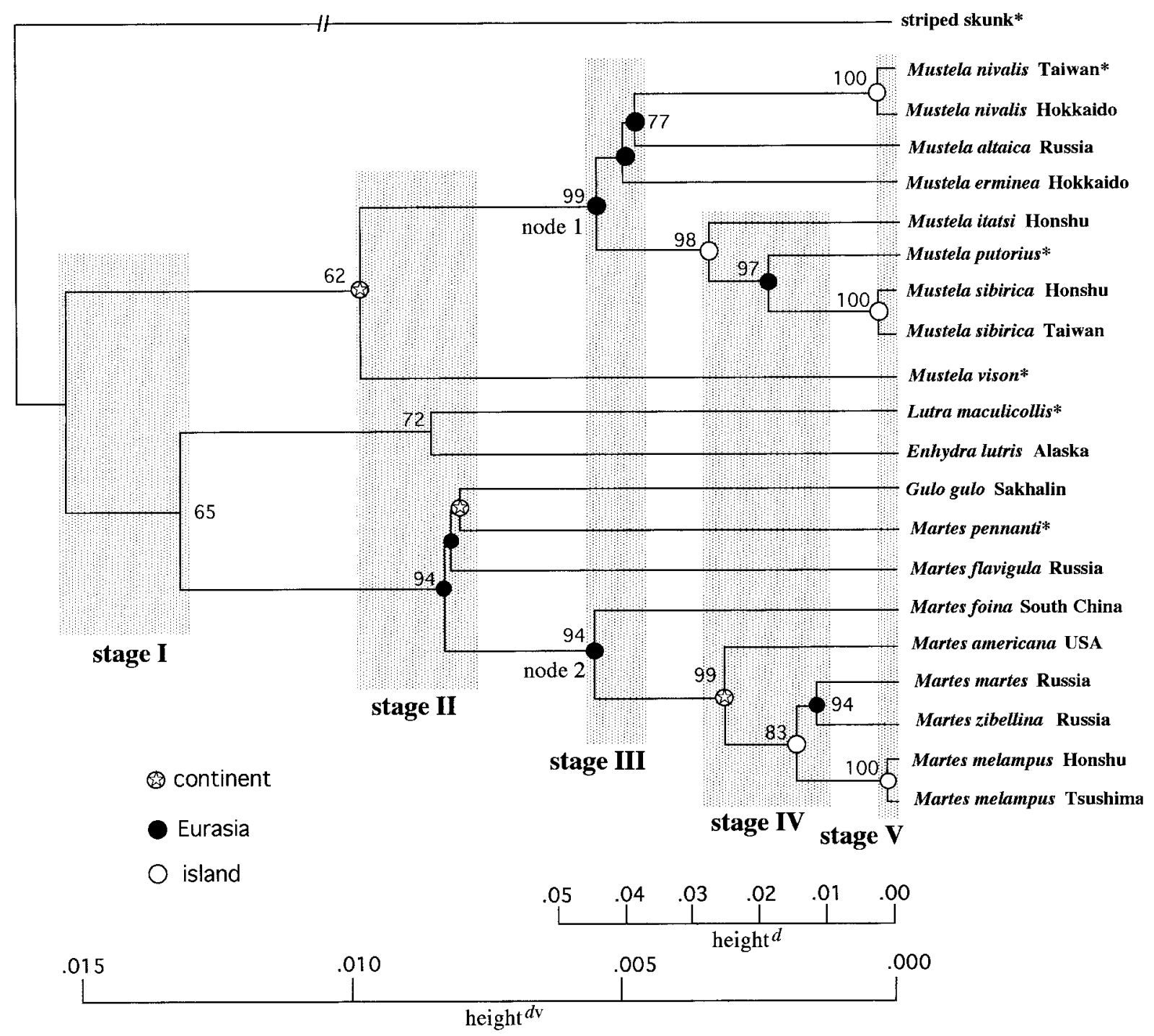

Fig. 2. A schematic presentation of the lineage differentiation of members of martens (Martes), weasels (Mustela), and their relatives based on linearized trees constructed from the complete sequences of the mitochondrial cytochrome $b$ gene from our data and the database (DDBJ/EMBL/GenBank). Sequences of the fisher Martes pennanti (AF057131), spot-necked otter Lutra maculicollis (AF057125), polecat Mustela putorius (X94925), and Taiwanese weasel Mustela nivalis (AB046612) were obtained from the database (Ledje and Arnason, 1996; Koepfli and Wayne, 1998; Hosoda et al., unpublished). The striped skunk (Mephitis mephitis, X94927) was used as an outgroup. The framework of this tree was based on a linearized tree constructed using transversional substitutions $(d \mathrm{v})$ and the NJ method for topology. Monophyletic groups of the Eurasian weasels (clade 1) and true martens (clade 2) are indicated. To confirm the resolution of the true martens and Eurasian weasels, we constructed linearized trees with both the substitutions $(d)$ of transversions and transitions. The heights $(d \mathrm{v}$ and $d)$ of node 1 were used to position the $d$ tree of the Eurasian Mustela. The $d$ tree of the true martens was set according to the height of node 2 of $d$. Bootstrap scores with 1000 replicates are given associated with each node (\%). Marks at nodes suggest the geographic forces that promoted the divergence; those operating between two continents (Eurasia and North America), within Eurasia, and among peripheral insular domains, such as the Japanese Islands and Taiwan. 
Enhydra, Martes, and Mustela (Fig. 2, stage I). With the current phylogenetic view, the traditional view of a monophyly of Martes and Mustela in the same subfamily Mustelinae was not likely to be supported, as Koepfli and Wayne (1998) already predicted. The next differentiation (stage II) is that between Mustela vison and other Mustela taxa in the clade Mustela, that between Gulo gulo, Martes flavigula, Martes pennanti, and the true martens in the clade Marten, and that between Enhydra lutris and Lutra maculicollis. Gulo gulo, which is sometimes treated as a member of the subfamily Guloninae in the traditional view, however, was consistently clustered into the clade Marten.

Divergences within the true Martes could be grouped into three stages (stages III-V): the first split was Martes foina from the others (stage III); the second was among the four species of Holoarctic, Martes americana, Martes martes, Martes melampus, and Martes zibellina (stage IV). Among the four, the mtDNA lineage that branched off first was an American lineage, Martes americana. The final stage of the evolution of the martens was the geographic differentiation within species (stage V). Each of the geographic domains, such as Taiwan and the Japanese Islands, tends to have specific types of mtDNA. In the lineages of Martes melampus, for example, populations of Honshu and the Tsushima Islands possessed different haplotypes (Fig. 2), as was documented by Kurose et al (1999a) and Hosoda et al. (1999).

The explanation for the radiation with three different steps is also applicable to the divergence within the Eurasian weasels (Mustela). The first stage (stage III) is the divergence of Mustela altaica, Mustela erminea, Mustela nivalis, and large-sized common Eurasian weasels (i.e., Mustela itatsi, Mustela sibirica and the Mustela putorius group). The second and third steps of divergence in the common weasels were those between species (stage IV) and within species (stage V), respectively. In the case of the Mustela putorius group, the intragroup diversification into "Mustela eversmanni," "Mustela lutreola," and "Mustela putorius" would have occurred at the final stage (stage V).

These findings for the phylogenetic relationships among the species of Mustela showed good consistency with those reported by Kurose et al. (2000), in which the cyt $b$ gene sequences of the nine species taxa of Mustela used in this study as well as a taxon of the domestic ferret Mustela furo were determined. These data lead us to conclude again that the members of the Mustela putorius group, including Mustela furo, possess quite similar cyt $b$ gene sequences.

\section{DISCUSSION}

We here recovered the intra- and inter-species phylogenetic relationships in the 19 extant species of Martes and
Mustela and their relative genera using the present and previous data of the cyt $b$ gene sequences. The taxa analyzed here cover all the seven extant species of Martes (Corbet and Hill, 1991). Here we address our interest in the evolutionary trends of the lineage diversification in the martens and weasels. To understand factors that shaped the phylogeny, it would be worth illustrating the temporal and spatial modes of differentiation, together with the molecular phylogenetic data and data from fossils and the geographic allocation of the species.

Temporal mode of differentiation Our basic understanding of the evolution of the mustelid group with respect to the temporal differentiation is that they have diverged stepwise as presented in Fig. 2; the differentiation can be grouped into the five radiations of stages I-V. The notion of a rapid diversification in a given evolutionary stage has been denoted by recent studies with carnivores. Koepfli and Wayne (1998), for example, suggest that lineage splitting of the giant otter, other otters, and weasels occurred within a short period of evolutionary time.

If we take it into account that divergence of the subfamily Mustelinae and Lutrinae occurred in the Early Miocene as inferred from fossil evidence of the earliest deposits (McKenna and Bell, 1997), the geological time of stage-I can be assumed to be 15-23 million years ago (Mya). Then the divergence rate is calculated to be $0.0013-0.0020$ $(d \mathrm{v})$ per Mya. Under these assumptions, the times of stages II, III, IV, and V can be assigned to the periods of Middle Miocene (10-14 Mya), Late Miocene (5-8 Mya), Pliocene (2-4 Mya), and Pleistocene ( 1 Mya), respectively. As to the time estimation for stage II which includes the lineage divergence of Lutra and Enhydra, it is consistent with the estimates made from fossil evidence (Willemsen, 1992) and molecular analysis (Koepfli and Wyne, 1998). Though these estimations should be reevaluated in future studies, the geological periods of the evolution of Martes and Mustela would be the past 10 million years from the late Tertiary to the Quaternary.

Geographic mode of differentiation From the tree of Fig. 2, it is clear how the geographic component is involved in species differentiation in the lineages of Martes and Mustela. Here we noticed three different geographic forces; those between continents, within continents, and among peripheral geographic domains of the Eurasian continent.

First, it is noticeable that two continents, Eurasia and America, are involved in the species differentiation. Among the lineages that we examined here, the American lineages are, Mustela americana, Mustela pennanti, and Mustela vison that have diverged at stages IV, II, and II, respectively (Fig. 2). Thus, it appears that there has been a dispersal of lineages across the continents from ancient 
times (e.g. $10 \mathrm{Mya}$ ) to present and this would be a major source of species and genetic diversity in terrestrial animals.

Second, it is apparent that there is intraspecific subdivision associated with regional geographic demarcation. For examples, Mustela erminea, Mustela nivalis, and Mustela sibirica tend to show intraspecific geographic differentiation along insular domains, such as the Japanese Islands and Taiwan. This is somehow consistent with the geological view that the Japanese Islands connected with the continent by land bridges, which were submerged and emerged several time during the glacious time, the last 1-2 Mya. In this respect, the Japanese Islands contributed to the genetic diversity in Mustela erminea and Mustela nivalis and to the species diversity among the true martens and the sibirica group, respectively, having two endemic species of Martes melampus and Mustela itatsi. It has been revealed that the peripheral geographic domains played important roles in species and genetic diversity in small mammals of moles (Tsuchiya et al., 2000), voles (Iwasa et al., 2000) and murid rodents (Suzuki et al., 1997; Serizawa et al., 2000).

The third notion is that speciation took place on the continent of Eurasia. Several cases of diversification involved in stages III and IV would be attributable to intraEurasian speciation, such as the differentiation of Martes martes and Martes zibellina with a strict border in Siberia (Anderson, 1970). The divergence of Martes foina and the other true marten would be another case of such differentiation. The morphological and karyological differentiation of three species of the putorius group (Mustela eversmanni, Mustela lutreola, and Mustela putorius; Graphodatsky et al., 1976) implies the occurrence of speciation events within the Eurasian continent. The available mtDNA data suggest the speciation events have been just accomplished or undergoing. Thus, it is worth documenting the status of the speciation in a future study.

The divergence process for the three sympatric groups of Mustela erminea, Mustela nivalis, and Mustela sibiricagroup (Mustela altaica, Mustela sibirica, and the Mustela putorius group) is not known but may have been triggered by geographic demarcation within the Eurasian continent in the early stages of differentiation. Alternatively, chromosomal rearrangement may have taken place during the speciation in the case of Mustela (Graphodatsky et al., 1976; Obara, 1991) which has distinguished chromosome rearrangements as depicted in Fig. 1. In contrast, the karyotypes of Martes are likely to be conserved among the species members. In Mustela, it is not certain, however, whether chromosomal change could affect the speciation or geographic differentiation of the mtDNA given in our present data. Mustela nivalis and Mustela erminea, for example, show a variable and an invariable state of chromosome variation, respectively (Obara, 1991), but there seems to be no considerable difference in the level of intraspecific variation of the mtDNA (Fig. 1).

As to the intraspecific subdivision of the mtDNA within the Eurasian continent in the species of Martes flavigula, Martes foina, Mustela erminea, and Mustela nivalis, which we accounted for here, it seems difficult to assess the mechanisms of differentiation, such as by estimating the geographic borders involved, through the analysis of only a small number of specimens and collection points (Fig. 1). In Mustela nivalis, for example, each haplotype tends to allocate to each geographic domain of European Russia, Far East Russia, and Korea but the lineage of the German haplotype positioned near Asian lineages in the NJ tree (Fig. 1). The observation of subdivision of mtDNA haplotypes in these species may imply allopatric differentiation and secondary admixture, cases of which have been assessed in many species of terrestrial mammals, such as the Asian elephant (Fernando et al., 2000). In the case of Martes foina, on the other hand, there may be geographic allocation in the mtDNA variation. A more extensive examination is needed. At any rate, the issue of intracontinental differentiation in animals with such potential for migration is certainly worth of study.

We would like to thank Hisashi Abe, Kay Fuhrman, Hirotsugu Fujino, Irina V. Kartavtseva, Yoshikazu Kitadani, Hong Lan, Yoshitaka Obara, Viacheslav Rozhnov, Hiroshi Sasaki, Kenkichi Sasaki, and Dmitry Ternovskii for their kind help for collection of samples. We would like to appreciate Keiko Serizawa, Masahiro A. Iwasa, and Jun Sato for their kind assistance in experimental work and preparation of this manuscript. This study was supported in part by Joint Research Project under the Japan-China Scientific Cooperation Program by Japan Society for the Promotion of Science (JSPS) and Natural Science Foundation of China (NSFC). The nucleotide sequences reported in this paper appear in the DDBJ, EMBL, and GenBank nucleotide sequence databases with the following accession numbers AB051234AB051289.

\section{REFERENCES}

Abe, H. (1994) A Pictorial Guide to the Mammals of Japan. Tokai University Press, Tokyo. (in Japanese)

Anderson, E. (1970) Quaternary evolution of the genus Martes. (Carnivora, Mustelidae). Acta Zoologica Fennica 130, 1-133.

Anderson, S., Bankier, A. T., Barrell, B. G., de Bruijn, M. H. L., Couslon, A. R., Drouin, J., Eperon, I. C., Nierlich, D. P., Roe, B. A., Sanger, F., Schreier, P. H., Smith, A. J. H., Staden, R., and Young, I. G. (1981) Sequence and organization of the human mitochondrial genome. Nature 290, 457-465.

Carr, S. M., and Hicks, S. A. (1997) Are There Two species of Marten in North America? Genetic and evolutionary Relationships within Martes. In: Martes: Taxonomy, Ecology, Techniques, and Management (eds.: G. Proulx, H. N. Bryant, and P. M. Woodard), pp. 15-28. Provincial Museum of Alberta, Edmonton.

Corbet, G. B., and Hill, J. E. (1991) A World List of Mammalian Species. (third edition). Oxford University Press, London.

Demboski, J. D., Stone, K. D., and Cook, J. A. (1999) Further perspectives on the Haida Gwaii glacial refugium controversy. Evolution 53, 2008-2012.

Fernando, P., Pfrender, M. E., Encalada, S. E., and Lande, R. 
(2000) Mitochondrial DNA variation, phylogeography and population structure of the Asian elephant. Heredity 84, 362-372.

Felsenstein, J. (1993) PHYLIP, version 3.5. Department of Genetics, University of Washington, Seattle.

Graphodatsky, A. S., Volobuev, V. T., Ternovsky, D. V., and Radjabli, S. I. (1976) G-banding of the chromosomes in seven species of Mustelidae (Carnivora). Zoologicheskii Zhurnal 55, 1704-1709. (in Russian with English Summary)

Hosoda, T., Suzuki, H., Yamada, T., and Tsuchiya, K. (1993) Restriction site polymorphism in the ribosomal DNA of eight species of Canidae and Mustelidae. Cytologia 58, 223-230.

Hosoda, T., Suzuki, H., Tsuchiya, K., Lan, H., Shi, L., and Kryukov, A. P. (1997) Phylogenetic relationships within Martes based on nuclear ribosomal DNA and mitochondrial DNA. In: Martes: Taxonomy, Ecology, Techniques, and Management (eds.: G. Proulx, H. N. Bryant, and P. M. Woodard), pp. 3-14. Provincial Museum of Alberta, Edmonton.

Hosoda, T., Suzuki, H., Iwasa, M. A., Hayashida, M., Watanabe, S., Tatara, M., and Tsuchiya, K. (1999) Genetic relationships within and between the Japanese marten Martes melampus and the sable M. zibellina, based on variation of mitochondrial DNA and nuclear ribosomal DNA. Mammal Study 24, 25-33.

Irwin, D. M., Kocher, T. D., and Wilson, A. C. (1991) Evolution of the cytochrome $b$ gene of mammals. J. Mol. Evol. 32, 128144.

Iwasa, M. A., Utsumi, Y., Nakata, K., Kartavtseva, I. V., Nevedomskaya, I. A., Kondoh, N., and Suzuki, H. (2000) Geographic patterns of cytochrome $b$ and Sry gene lineages in gray red-backed vole, Clethrionomys rufocanus (Mammalia, Rodentia) from Far East Asia including Sakhalin and Hokkaido. Zool. Sci. 17, 477-484.

Jordan, M. (1995) An introduction to the Mustelidae. In: Husbandry Handbook for Mustelidae" (ed: J. Partridge), pp. 1-14. The Association of British wild Animal Keepers, U.K.

Kimura, M. (1980) A simple method for estimating evolutionary rates of base substitutions through comparative studies of nucleotide sequences. J. Mol. Evol. 16, 111-120.

King, C. M. (1989) The Natural History of Weasels \& Stoats. Christopher Helm, London.

Koepfli, K. P., and Wayne, R. K. (1998) Phylogenetic relationships of otters (Carnivora : Mustelidae) based on mitochondrial cytochrome $b$ sequences. J. Zool. 246, 401-416.

Kumar, S., Tamura, K., and Nei, M. (1993) MEGA: molecular evolutionary genetics analysis, version 1.01. The Pennsylvania State University, University Park, Pa.

Kurose, N., Masuda, R., Siriaroonrat, B., and Yoshida, M. C. (1999a) Intraspecific variation of mitochondrial cytochrome $\mathrm{b}$ gene sequences of the Japanese marten Martes melampus and the sable Martes zibellina (Mustelidae, Carnivora, Mammalia) in Japan. Zool. Sci. 16, 693-700.

Kurose, N., Masuda, R., and Yoshida, M. C. (1999b) Phylogeographic variation in two Mustelines, the least weasel Mustela nivalis and the ermine M. erminea of Japan, based on mitochondrial DNA control region sequences. Zool. Sci. 16, 971-977.

Kurose, N., Abramov A. V., and Masuda, R. (2000) Intrageneric diversity of the cytochrome b gene and phylogeny of Eurasian species of the genus Mustela (Mustelidae, Carnivora). Zool. Sci. 17, 673-679.
Ledje, C., and Arnason, U. (1996) Phylogenetic analyses of complete cytochrome $b$ genes of the order Carnivora with particular emphasis on the Caniformia. J. Mol. Evol. 42, 135144.

McKenna, M. C., and Bell S. K. (1997) Classification of Mammals: above the species level. Columbia Unversity Press, New York.

Masuda, R., and Yoshida, M. C. (1994a) Nucleotide sequence variation of cytochrome $b$ genes in three species of weasels, Mustela itatsi, Mustela sibirica, and Mustela nivalis, detected by improved PCR product-direct sequencing technique. J. Mammal. Soc. Jpn. 19, 33-43.

Masuda, R., and Yoshida, M. C. (1994b) A molecular phylogeny of the family Mustelidae (Mammalia, Carnivora), based on comparison of mitochondrial cytochrome $b$ nucleotide sequences. Zool. Sci. 11, 605-612.

Obara, Y. (1991) Karyosystematics of the mustelid carnivores of Japan. Honyurui Kagaku (Mammalian Science) 30, 197220. (in Japanese)

Saitou, N., and Nei, M. (1987) The neighbor-joining method: a new method for reconstructing phylogenetic trees. Mol. Biol. Evol. 4, 406-425.

Serizawa, K., Suzuki, H., and Tsuchiya, K. (2000) A phylogenetic view on species radiation in Apodemus inferred from variation of nuclear and mitochondrial genes. Bichem. Genet. 38, 27-40.

Suzuki, H., Minato, S., Tsuchiya, K., and Fokin, I. M. (1997) Phylogenetic position and geographic differentiation of the Japanese dormouse, Glirulus japonicus, revealed by variations in rDNA, mtDNA and the Sry gene. Zool. Sci. 14, 167-173.

Suzuki, H., Tsuchiya, K., and Takezaki, N. (2000) A molecular phylogenetic framework for the Ryukyu endemic rodents Tokudaia osimensis and Diplothrix legata. Mol. Phylogenet. Evol. 15, 15-24.

Takezaki, N., Rzhetsky A., and Nei, N. (1995) Phylogenetic test of the molecular clock and linearized trees. Mol. Biol. Evol. 12, 825-833.

Tamura, K., and Nei, M. (1993) Estimation of the number of nucleotide substitution in the control region of mitochondrial DNA in humans and chimpanzees. Mol. Biol. Evol. 10, 512-526.

Tate, G. H. H. (1947) Mammals of Eastern Asia. Macmillan Co., New York.

Tsuchiya, K., Suzuki, H., Shinohara, A., Harada, M., Wakana, S., Sakaizumi, M., Han, S. H., Lin, L. K., and Kryukov, A. P. (2000) Molecular phylogeny of East Asian moles inferred from the sequence variation of the mitochondrial cytochrome $b$ gene. Genes Genet. Syst. 75, 17-24.

Wayne, R. K., Benveniste, R. E., Janczewski, D. N., and O'Brien, S. J. (1989) Molecular and biochemical evolution of the Carnivora. In: Carnvore Behavior, Ecology, and Evolution (ed.: J. L. Gittleman), pp. 465-494. Prenum Press, New York.

Willemsen, G. F. (1992) A revision of the Pliocene and Quaternary Lutrinae from Europe. Scripta Geol. 101, 1-115.

Wozencraft, W. C. (1993) Order Carnivora. In: Mammal Species of the World (second edition, eds.: D. E. Wilson, and D. M. Reeder), pp. 279-348. Smithsonian Institute Press, Washington and London.

Youngman, P. M. (1982) Distribution and systematics of the European Mink Mustela lutreola Linnaeus 1761. Acta Zoologica Fennica 166, 1-48. 